\title{
Development of a decision support tool: Preliminary analysis to improve field data collection in Kathiraveli Village, Sri Lanka
}

\author{
Tom Le Cerf \\ Engineers Without Borders Australia, Melbourne \\ Tom.lecerf@hotmail.com
}

\begin{abstract}
This paper focuses specifically on the development of a water balance model that will support agricultural decision making for the irrigation field and water supply tanks. The study based on an irrigation system within Kathiraveli, an isolated war affected village in north-eastern Sri Lanka. The irrigation system is used to deliver water to approximately 100 farmers. Estimates or measurements of water availability at the start of the cultivation period are able to be combined with estimates of likely future inflows based on previous rainfall to determine optimum crop selection and crop area allocation. The model consists of three modules: a crop water requirement calculator, a water tank balance model, and a model which simulates the storage in the permanent wetland attached to the irrigation tank. Due to limited budgets and timeframes to obtain input data, a careful balance between accuracy, complexity and cost needed to be reached to ensure that the model can be accurate for its intended use. To do this the model was ran initially under baseline conditions. A sensitivity analysis was then performed to assess the importance of major variables; the outcomes of this study were used to prioritise the collection of field data.
\end{abstract}

KEYWORDS: Irrigation, water balance model, calibration.

1

\section{INTRODUCTION}

Recent droughts, war and cyclones have reduced the resilience of irrigation systems in north-eastern Sri Lanka. Climate change is predicted to further stress these systems by reducing rainfall totals and increasing irrigation water requirements (De Silva et al, 2007). Across Sri Lanka an estimated 7500 irrigation tanks (small dams) currently support cultivation (Panabokke et al, 2002). These irrigation tanks are the first constructed wetlands with the oldest irrigation tanks dating back to 200 AD (Mahatantila et al, 2008). Due to the large number of irrigation tanks across the country and the relatively limited resources available to farming communities the impact of optimising the use of water stored within the tanks could be significant. The study site is located in an isolated area on the east coast of Sri Lanka and only limited existing data is available due to the recently concluded civil war. The study site (Kathiraveli) contains a permanent wetland (Viloo) which is fed by both a regional river and local catchment of 150 hectares. The Viloo is connected to an irrigation tank which directly irrigates 60 hectares of land.

Water balance models have been used since the 1940s for assessing the seasonal patterns of water supply and irrigation demand as well as catchment hydrology and the impacts of climate change ( $\mathrm{Xu}$
\& Singh, 1998). Despite this they are expensive and relatively inaccessible for the local Sri Lankan Agricultural Planning Authorities due to difficulty of obtaining data. The challenge for this paper is to develop a model that utilises easily obtainable locally available data and existing regional data and equations. A balance between existing regional data and local field data is reached to allow the simulation and planning for the upcoming agricultural season. The model has been developed within Microsoft Excel $^{\mathrm{TM}}$ to ensure that it can be made easily accessible and simple to use and refine for competent excel users. It is hoped that the model will be able to be utilised by agricultural officers to inform input and thereby reduce the risk of water shortages and increase water efficiency. Preliminary modelling will enable more focused and effective data collection and therefore the main focus of this paper is to investigate the potential of preliminary modelling to help refine the data collection effort.

\section{WATER BALANCE MODEL}

The water balance model has been designed to mirror the natural system at Kathiraveli Village (Figure 1 ). The three compartments of the model are all connected through culverts and include the Viloo, the Irrigation Tank and the Irrigation Fields. The Viloo and Irrigation Tank both contain inflows from 


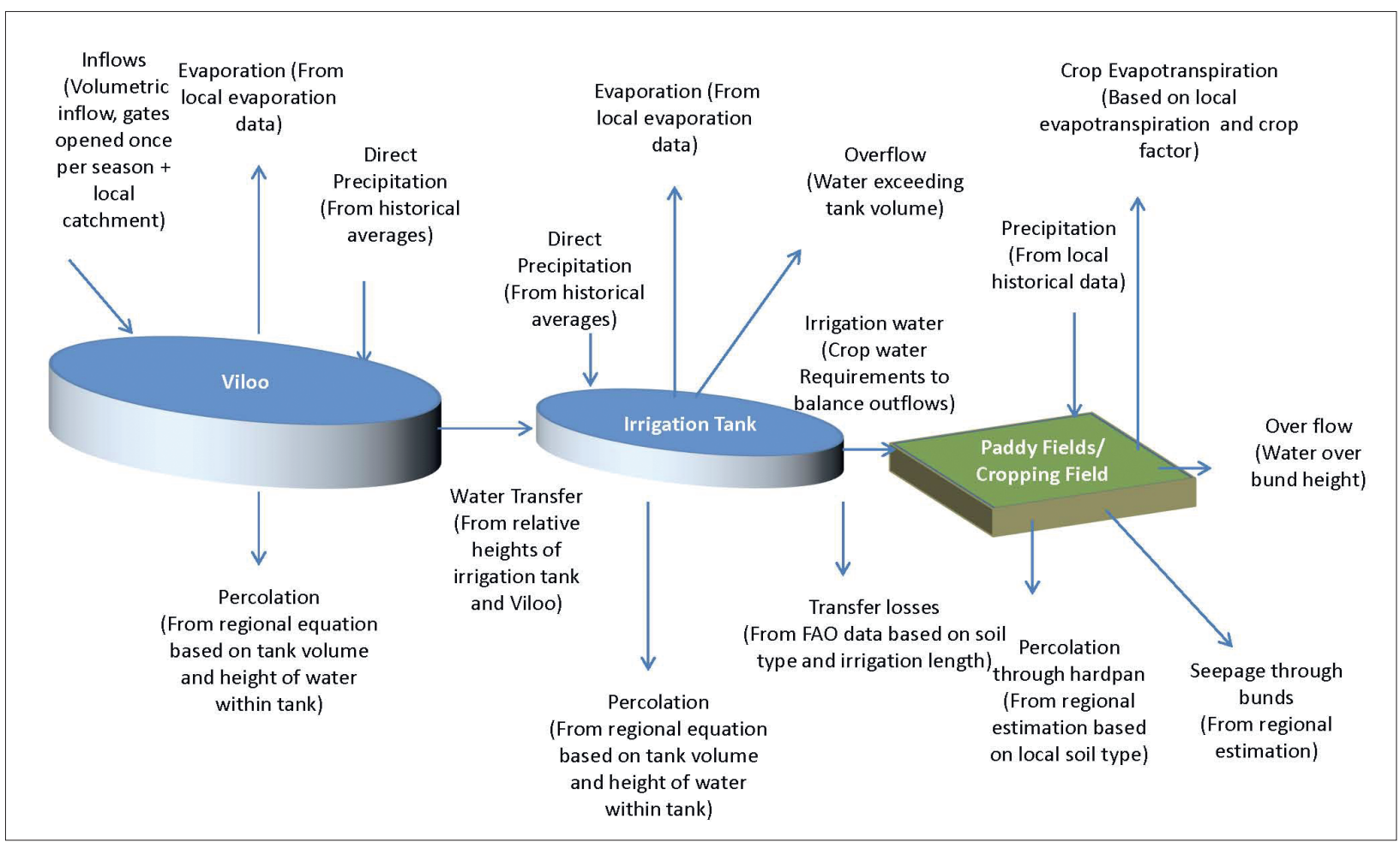

Figure 1: Water balance model layout including inflows and outflows of the three model components. Abbreviations: FAO- United Nations Food and Agricultural Organisation.

direct rainfall and a percolation component that is relative to the volume of water within the tank. The Viloo also includes a volumetric inflow at the start of the irrigation season and occurs during a river flood event. It is input as a measurement of the depth of water within the Viloo, the model then calculates the volume of water within the Viloo based on storage height relationships. A hydrological model is also incorporated into the Viloo it utilises simulates runoff generated in the local catchment. The hydrological model has been developed using equations revised by Jayatilaka et al (2001) and model parameters from Sakthivadivel et al (1996).

The Irrigation Tank has an overflow component that occurs when water within the irrigation tank exceeds the height of the flood weir. Transfer of water between the two irrigation tanks is determined by the relative heights of water within the Irrigation Tank and Viloo. The irrigation fields allow the simulation of three different non-rice crops and a rice crop. Evapotranspiration is determined using the United Nations Food and Agricultural Organisation (FAO) derived single co-efficient equation (Allen et al. 1998). Irrigation efficiency can also be adjusted for each crop independently; the seepage rates for rice can also be adjusted.

\section{BASELINE SCENARIO}

The baseline scenario is considered the best conservative estimate of actual conditions at
Kathiraveli in any given season. Seepage and percolation from a tank is proportional to its storage (Matsuno et al, 2003). The average rate of percolation and seepage of an irrigation tank is $0.5 \%$ of the storage volume per day. However, $0.3 \%$ is used for the Viloo due to the shallow water table present on site (Matsuno et al, 2003). For the hydrological model estimates of the standard expected parameters for the Sri Lankan context have been used (Run off Coefficient 0.25 and delay $=150 \mathrm{~mm}$ ) (Sakthivadivel et al, 1996). The local catchment area has been estimated as 150 hectares using Shuttle Radar Topography Mission $90 \mathrm{~m}$ data.

The irrigation fields' initial water requirements is estimated as $50 \mathrm{~mm}$ however as seasonal rains are utilised for land preparation, this is a conservative estimate (Department of Agriculture, 2006). Transfer losses (water lost during delivery of water from the irrigation tank to the irrigation fields) are estimated as $30 \%$ of total irrigation water (Brouwer et al, 1989). This is reflective of the local soil type. Crop factors developed specifically for Sri Lanka have been used (Manchnayake \& Bandara, 1999). Seepage in the paddy fields has been calculated through studies of similar soil types as $8 \mathrm{~mm} /$ day (Manchnayake \& Bandara, 1999). Rainfall has been calculated using rainfall data from nearby weather stations.

\subsection{Results}

To simulate an irrigation season the above parameters were input into the model. All parameters were kept 
constant while the maximum cropping area was adjusted to find the maximum possible cropping area that could be irrigated while ensuring that the irrigation tank didn't become dry. The largest area that could be irrigated with available water (maximum cropping area) over the Maha Season was 30 hectares. Increasing the cultivation area above this results in the irrigation tank running dry.

\subsection{Water balance}

Figure 2 shows changes in water storage over the simulation period within the Viloo. A slow decline of the total water storage is observed. The outflows to the irrigation tank have the largest influence on the water balance. Evaporation has the second largest influence. Precipitation and inflow from the local catchment are the two smallest contributions; this is a clear indication of why the steady decline in the Viloo storage occurs.

The Irrigation Tank also undergoes a similar decline throughout the season. Initially the inflows from the Viloo maintain the total volume within the tank to around 500,000 $\mathrm{m}^{3}$; however, after the first month the amount of water needed to change the relative height within the irrigation tank begins to reduce due to reductions in cross sectional area. Therefore, the amount of water transferred from the Viloo begins to reduce as the transfer of water becomes restricted by the storage capacity within the tank that is below the current water surface height of the Viloo.

By comparing rainfall and evapotranspiration data over time, the irrigation scheduling starts after the peak in rainfall occurs. With no further inflows from the river and increasing irrigation water requirements over the irrigation period it seems unlikely that any water will be able to be stored for irrigation in the Yala (dry) season; despite making changes to the input parameters.

The irrigation water requirements slowly increase as the evapotranspiration increases and precipitation. Figure 3 shows that the largest component of the irrigation requirement of rice is seepage. Evaporation however is also a significant factor as effective precipitation is considerably less then evaporation. Therefore seepage rates within the paddy field are critically important in determining the water balance.

The most significant factor within the Viloo is outflows to the Irrigation Tank that are required to irrigate the land (Figure 4 and Figure 5). Evaporation is a major component of the water balance in all three components of the model (Viloo, Irrigation Tank and Paddy Fields).

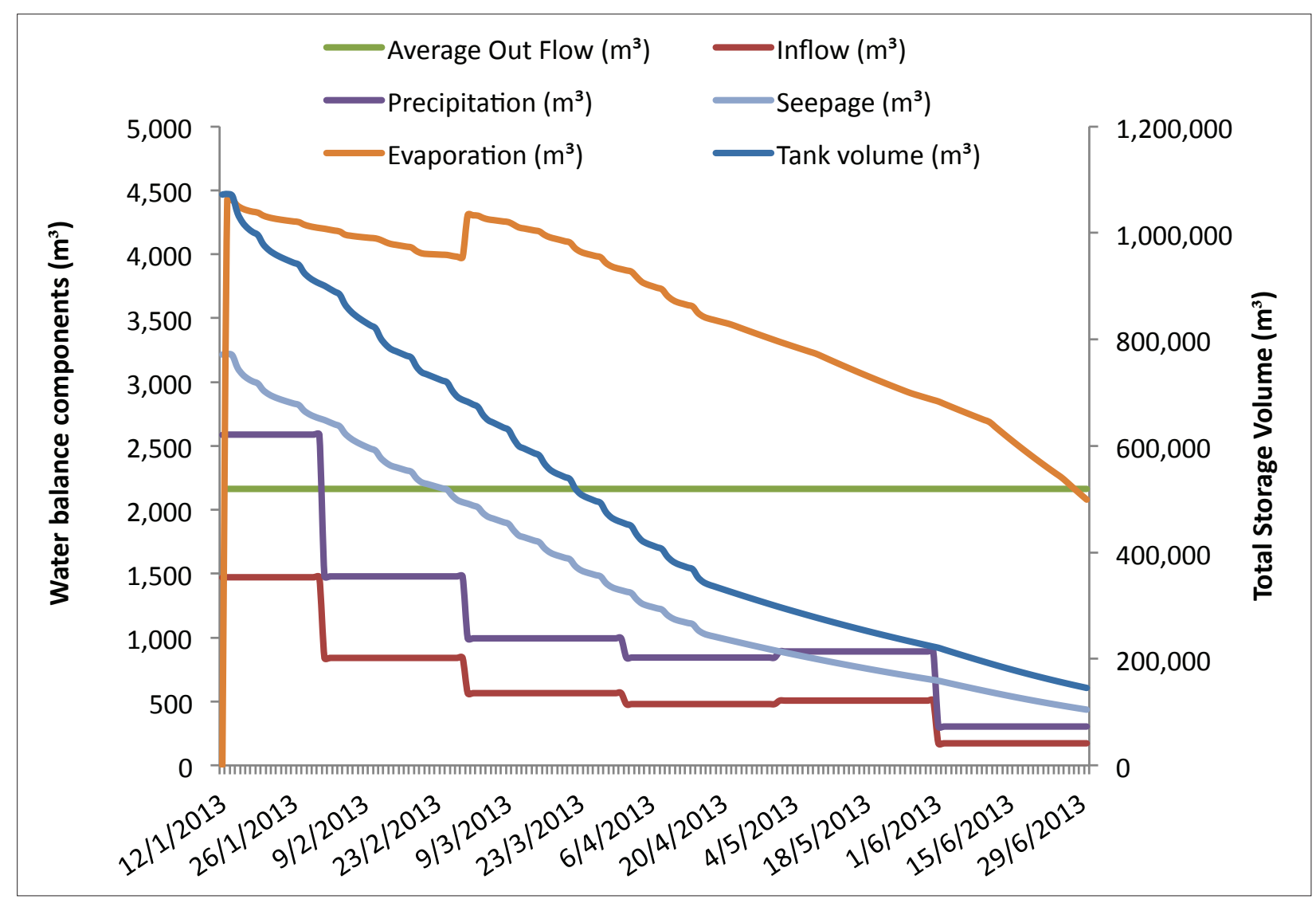

Figure 2: Baseline simulation water balance components within the Viloo. 


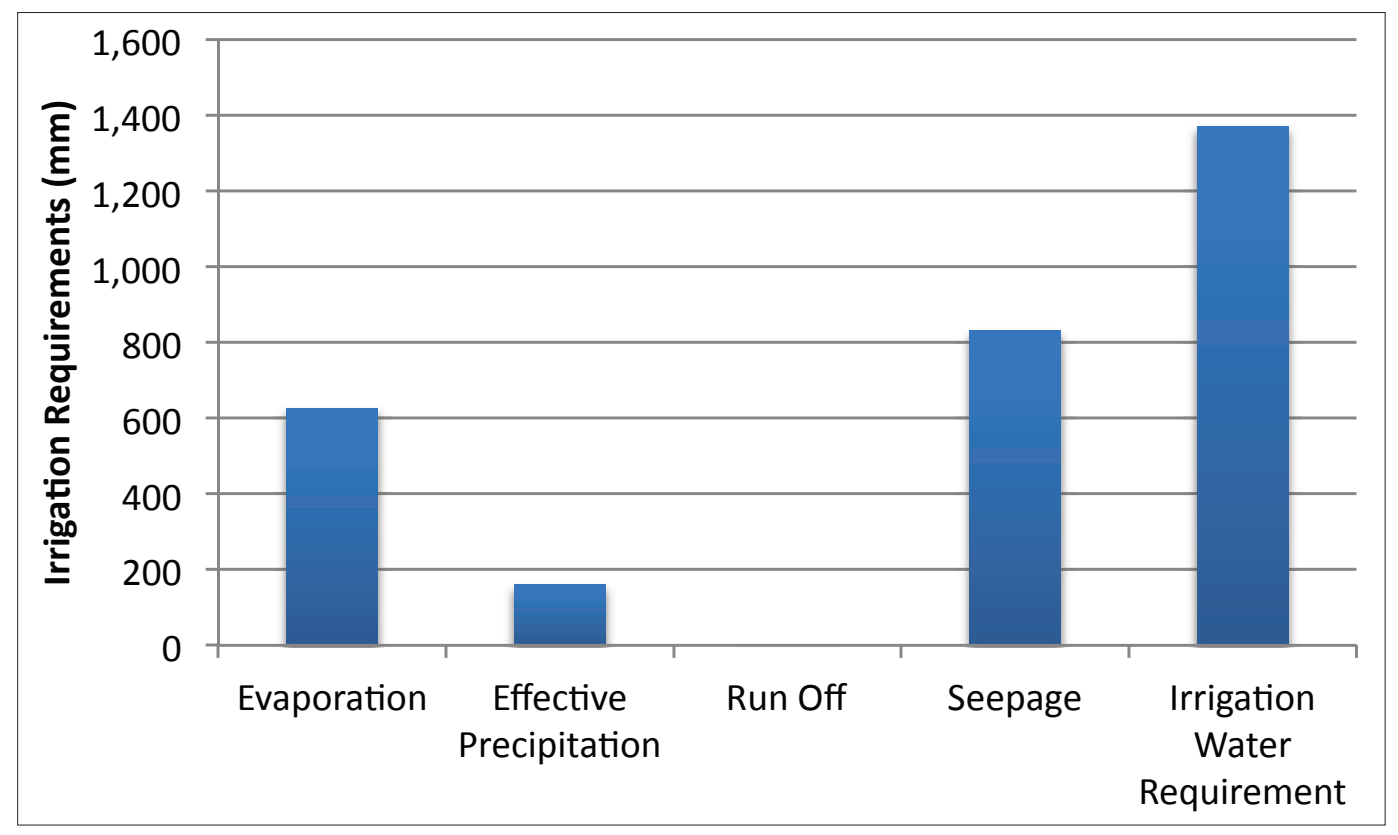

Figure 3: Paddy field inflows and outflows. Irrigation water requirement is the total of evaporation, effective precipitation, runoff and seepage.

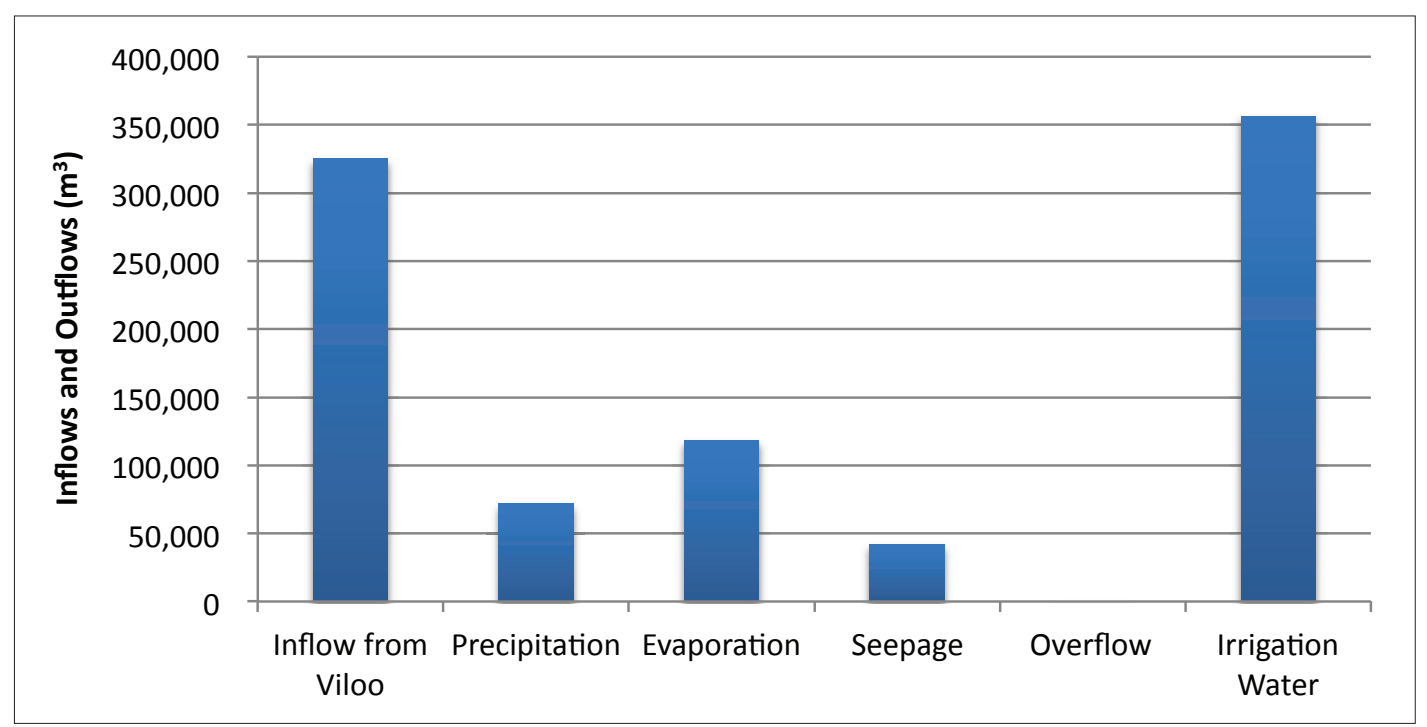

Figure 4: $\quad$ Irrigation Tank inflows and outflows.

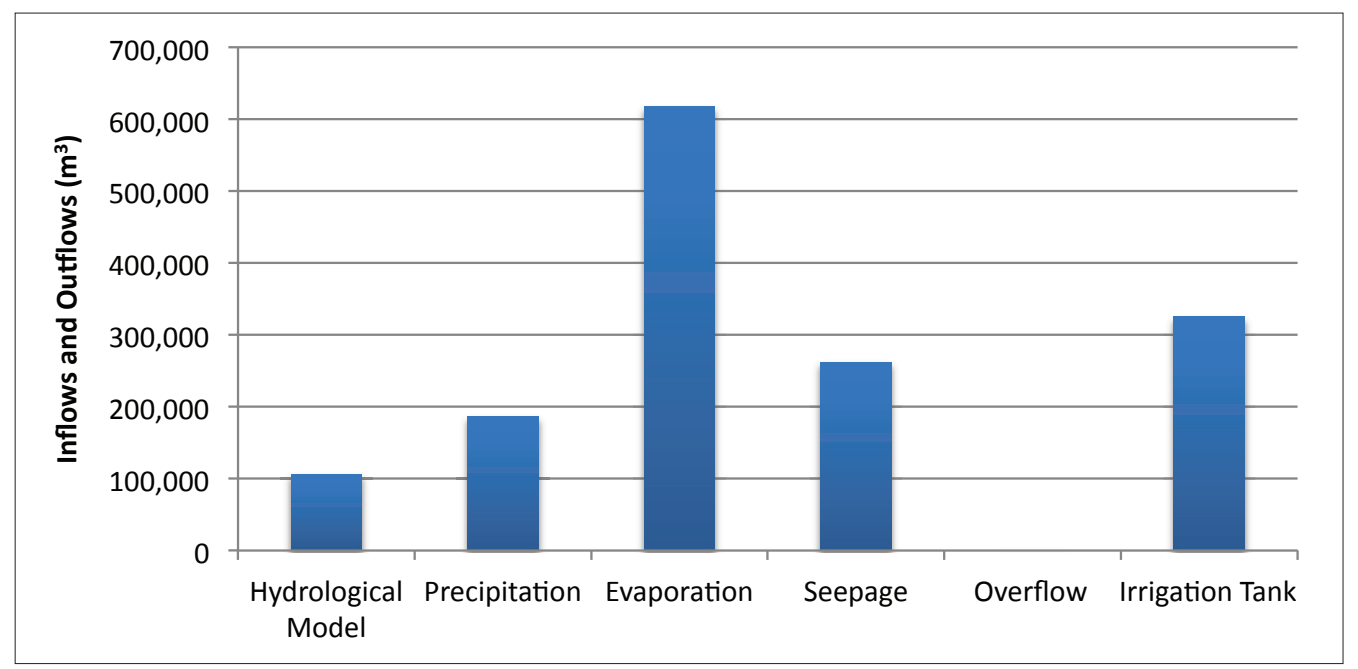

Figure 5: Viloo inflows and outflows. Hydrological model includes local catchment inflows. 


\subsection{Rainfall}

To investigate the impacts of the highly variable rainfall that Kathiraveli receives the daily time series from a number of different years is used with the impacts to cultivation area recorded. The years tested are included below and outcomes are discussed below in Table 1. The high variability of rainfall significantly impacts the potential total cultivation area. There is a four-fold difference between the best and worst year.

\subsection{Paddy seepage}

Seepage values are based on estimates of seepage from similar soil types. The impacts of halving and doubling the seepage rates are examined to provide an estimate of the model to their sensitivity.

A change in the seepage rate within the paddy field has considerable impacts to the total cultivation area. A halving of the seepage rate resulted in an increase in the possible irrigation area by almost $25 \%$. Doubling the seepage rate reduced the area able to be irrigated by over $25 \%$. Therefore it can be concluded that the seepage rate of the paddy fields is an important parameter to be considered with assessing water requirements for the system.

\subsection{Tank and Viloo seepage}

Seepage rates are taken as estimates from a typical irrigation tank within Sri Lanka with a slight adjustment made to the Viloo as it is very large and also has a shallow water table (Matsuno et al, 2003).

Seepage rates from the Irrigation Tank and Viloo both are able to significantly influence the amount of area that is able to be cultivated. There are a number of commonly used methods for estimating seepage within an irrigation tank. This includes the percentage of volume method which is based on seepage being relative to the volume of water within the tank, the relative height method includes the relative height of water within the tank to estimate seepage rates (Matsuno et al, 2003). If using the percentage of volume method seepage rates are significantly lower than the relative height method. Doubling the seepage loss rate of $0.5 \%$ per day for the Irrigation tank and $0.3 \%$ for the Viloo significantly reduces water available for cultivation, as large amounts of water are lost to the subsurface. This is slightly less sensitive to changes than changes in paddy seepage.

\subsection{Evapotranspiration}

Changes in evaporation result in significant changes in the water balance in all compartments of the model. The obtained evaporation data is from 1985 and reported as monthly average evaporation from a reference crop (Manchnayake \& Bandara, 1999). Therefore it may be possible that changes have occurred to the seasonal evaporation patterns since that time. Out of all the tested variables relative changes to evaporation make the largest changes to maximum cultivation area. This highlights that updated and accurate evaporation data is vitally important.

Table 1: Impact of annual rainfall on cultivation area.

\begin{tabular}{|c|c|c|l|}
\hline Year & $\begin{array}{c}\text { Annual } \\
\text { Rainfall } \\
\text { (mm) }\end{array}$ & $\begin{array}{c}\text { Maximum } \\
\text { Cultivation } \\
\text { Area (ha) }\end{array}$ & \multicolumn{1}{|c|}{ Observations } \\
\hline 1995 & 1085.8 & 26.57 & $\begin{array}{l}\text { Significant January rains mean that even though yearly total is } \\
\text { low, the area available to be cultivated is only slightly less than the } \\
\text { baseline scenario. }\end{array}$ \\
\hline 1996 & 1403.4 & 18.78 & $\begin{array}{l}\text { The observed reduction is caused by a slight decrease in effective } \\
\text { precipitation which is significant when spread over entire cropping } \\
\text { area. No significant rainfall during cultivation season. }\end{array}$ \\
\hline 1989 & 1489.5 & 30.81 & $\begin{array}{l}\text { High February rainfall result in significant inflows from local } \\
\text { catchment and direct on tank rainfall. }\end{array}$ \\
\hline 1984 & 2299.4 & 36.33 & $\begin{array}{l}\text { A number of rainfall events throughout the season contribute to } \\
\text { inflows and also reduce the crop water requirements. }\end{array}$ \\
\hline
\end{tabular}




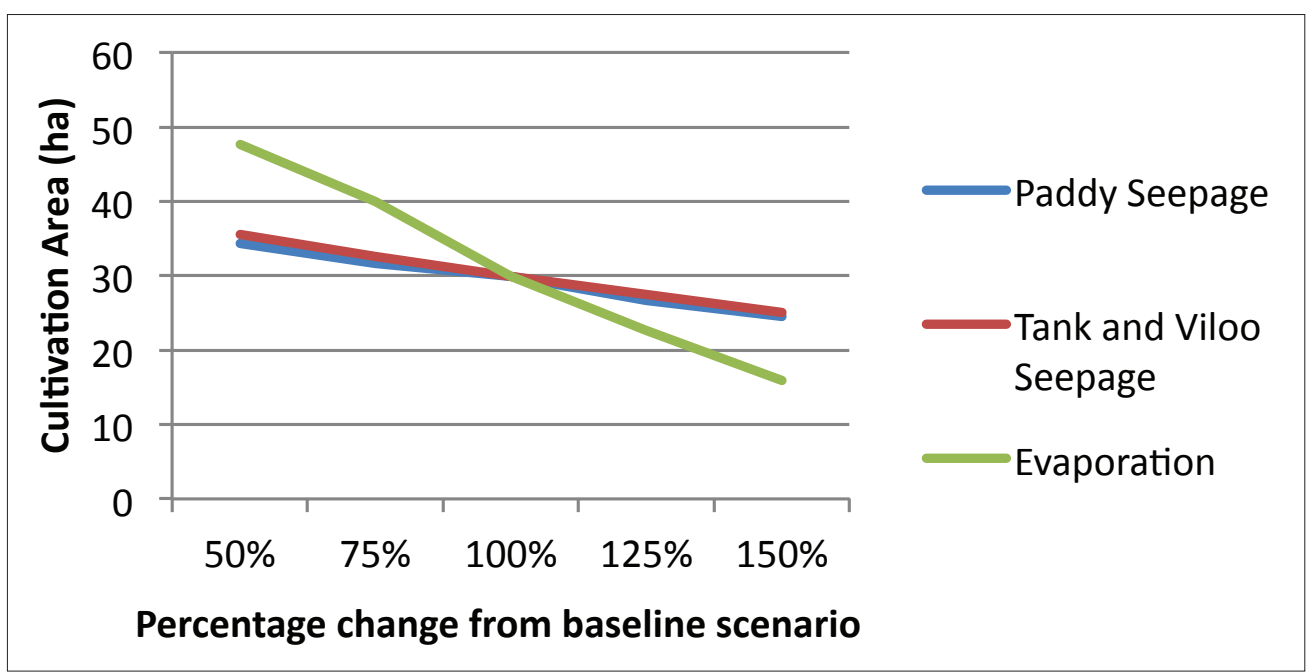

Figure 6: Uncertainty analysis comparing variations in seepage rates and evaporation rates.

\section{CALIBRATION AND DATA COLLECTION}

Currently little data exists for the study region and therefore the next stage of the project will need to focus on calibrating the model's predictions and performance. Currently the water balance model utilises best estimate regional predictions of model equations and input characteristics however as shown in sensitivity analysis changes to any of these parameters can significantly influence model performance and predictions.

For the upcoming agricultural season a number of gauges have been installed to monitor water levels within the Verugal Aru (the major river which feeds the irrigation system). Understanding the required level and flow rate of water within the river to fill the Viloo will be important in enhancing the management of inflow gates. Understanding the inflow characteristics of the system will help determine if an earlier start to the irrigation season could be possible by undertaking multiple inflow events. The Viloo will also be monitored during the opening of the inflow gates to help further understand the operation of the system.

Other key data that need to be obtained for the calibration of the model include:

- Rainfall and evapotranspiration data from a local weather station for the upcoming agricultural season. This data is important for accurately modeling the upcoming season. The sensitivity to both rainfall and evaporation indicate the need for further analysis to determine the influence of spatial heterogeneity at the study site.

- Future monitoring of water levels within the Viloo and Irrigation Tank during the agricultural season will allow the model to be easily calibrated. By ensuring that rainfall and evapotranspiration data is accurate, seepage within the irrigation tank would be able to be calculated. Data ideally will be collected on a daily or weekly basis for the entire season.

- Changes in water levels within paddy fields during irrigation water application are another simple parameter that could be obtained. This data would significantly reduce uncertainty within the model and would be relatively inexpensive requiring only a ruler and a clock that could be used to record changes in water level across a day (or multiple days).

\section{CONCLUSION}

After important considerations, such as the highly variable inter-annual and intra-annual rainfall and the history of irrigation within Sri Lanka, the model was applied to a baseline scenario composed of best estimates of actual conditions. Uncertainty analysis highlighted that changes in all of seepage, evaporation and rainfall can have significant impacts to model predictions. The uncertainty analysis and baseline model run helped highlight the relative importance of each input parameter and determine a simple data collection schedule for the upcoming irrigation season. The model is intended to be utilised at irrigation planning meetings at the start of the irrigation season to allocate cropping areas for the upcoming agricultural season.

\section{REFERENCES}

Allen, R.G., Pereira, L.S., Raes, D. \& Smith, M. 1998, Crop evapotranspiration - Guidelines for computing crop water requirements - FAO Irrigation and drainage paper 56, FAO - Food and Agriculture Organization of the United Nations, Rome, Italy.

Brouwer, C., Prins, K. \& Heibloem, M. 1989, Irrigation Water Needs, Irrigation Scheduling, FAO, Rome. Italy. 
De Silva, C.S., Weatherhead, E.K., Knox, J.W. \& Rodriguez-Diaz, J.A. 2007, 'Predicting the impacts of climate change - A case study of paddy irrigation water requirements in Sri Lanka', Agricultural Water Management, vol. 93, no. 1-2, pp. 19-29.

Department of Agriculture, 2006, Water management, viewed 1 May 2013, <http://www.agridept. gov.1k/index.php / en / component/content / article/207/905>.

Jayatilaka, C., Sakthivadivel, R., Shinogi, Y., Makin, I.W. \& Witharana, P. 2001, Predicting water availability in irrigation tank cascade systems: The cascade water balance model. Research Report 48, Colombo, Sri Lanka.

Mahatantila, K., Chandrajith, R., Jayasena, H.A.H. \& Ranawana, K.B. 2008, 'Spatial and temporal changes of hydrogeochemistry in ancient tank cascade systems in Sri Lanka: evidence for a constructed wetland', Water and Environment Journal, vol. 22, no. 1, pp. 17-24.
Manchnayake, P. \& Bandara, C.M.M. 1999, Water Resources of Sri Lanka, Colombo, Sri Lanka.

Matsuno, Y., Tasumi, M., Hoek, W., Sakthivadivel, R \& Otsuki, K 2003, 'Analysis of return flows in a tank cascade system in Sri Lanka', Paddy and Water Environment, vol. 1, no. 4, pp. 173-81.

Panabokke, C.R.S., Ramasamy; Dias Weerasinghe, Asoka; 2002, Evolution, present status and issues concerning small tank systems in Sri Lanka, International Water Management Institute.

Sakthivadivel, R., Fernando, N., Panabokke, C. \& Wijayaratna, C. 1996, Nature of small cascade systems and a framework for rehabilitation of tanks within them, International Water Management Institute.

Xu, C.Y. \& Singh, V.P., 1998, 'A Review on Monthly Water Balance Models for Water Resources Investigations', Water Resources Management, vol. 12 , no. 1 , pp. 20-50. 